\title{
Radium-226 in Magela Creek, northern Australia: Application of protection limits from radiation for humans and biota
}

\author{
C. Sauerland ${ }^{1}$, P. Martin ${ }^{2}$ and C. Humphrey ${ }^{1}$ \\ ${ }^{1}$ Environmental Research Institute of the Supervising Scientist, Darwin, NT 0801, Australia, \\ e-mail: Claudia.Sauerland@deh.gov.au \\ ${ }^{2}$ Agency's Laboratories Seibersdorf, International Atomic Energy Agency, 1400 Vienna, \\ Austria, e-mail: P.Martin@iaea.org
}

\begin{abstract}
In the context of protecting the environment from the effects of ionizing radiation associated with uranium mining, the alpha-emitting radium 226 is the uranium progeny of most interest as it is known to bioaccumulate and confers a high effective dose to biota. For the Ranger uranium mine in northern Australia, total radium 226 activity concentrations were determined in water samples from Magela Creek both upstream and downstream of the mine over two years. Those data were evaluated within three different frameworks and were found to comply with respective limits: human dose estimations, site-specific guideline 'trigger' values for ecosystem health (derived from the distributional properties of values from a reference (upstream) dataset) and estimations of absorbed dose to freshwater mussels residing in Magela Creek (long-lived organisms with high rate of uptake and exposure). We propose that the currently-used, human-dose limit of $10 \mathrm{mBq} . \mathrm{L}^{-1}$ be applied to the difference of the wet season arithmetic means calculated for the upstream and downstream locations. In addition, the statistically derived trigger values (e.g. a moving $80^{\text {th }}$ percentile of upstream data) could be used to assess if radium 226 measured downstream of the uranium mine has resulted in an additional dose to biota.
\end{abstract}

\section{INTRODUCTION}

The Magela Creek system is located in the tropical monsoonal belt of northern Australia, which is characterised by contrasting wet and dry seasons. Magela Creek drains a catchment about half of which lies upstream of the Ranger open-cut uranium mine. The risk to the downstream aquatic systems is from dispersion of mine waste-waters arising from run-off of rainfall during the wet season or from leaching of contaminated waters via a groundwater pathway. The surrounding ecosystems form part of the World-Heritage listed Kakadu National Park and require a high level of protection for its diverse flora and fauna. Further, the local Aboriginal population rely to a considerable extent on traditional food sources that represent potential sources of radiological dose. The potential bioaccumulation of radium 226 (Ra-226) in aquatic biota of the region is well documented [1-3]. Martin et al. [1] calculated that, in the event of a release of waters from the mine-site, the resultant effective dose to members of the critical group (the Aboriginal population living downstream of the mine) would be dominated by Ra-226. As a result receiving water standards for the radiological dose to humans have been set based on Ra-226.

For the Ranger uranium mine, physical and chemical monitoring (including radionuclide concentrations) is conducted at locations upstream and downstream to ensure that receiving water standards have been met. Biological monitoring (creekside assays, biota community structure, bioaccumulation of selected contaminants and possible toxicological effects) addresses the conservation of biological diversity and provides early warning of adverse impacts. In this paper we evaluate monitoring data for Ra-226 within three different frameworks: (i) trigger values based on 
human dose estimations and following recommendations of the International Commission on Radiological Protection [1, 4, 5], (ii) trigger values for the protection of ecosystem health based on the revised Australian and New Zealand Water Quality Guidelines [6], and (iii) a radiological dose assessment of Ra-226 for aquatic biota living in receiving waters. For the last approach, dose rates are calculated from equilibrium concentrations of radionuclides in biota using concentration factors between biota and water, and a spreadsheet program developed by Copplestone et al [7]. This case study explores the emerging issue of developing guidelines for the protection of local aquatic ecosystems from radiological dose.

\section{METHODS}

Creek water samples $(1 \mathrm{~L})$ were collected from two sites on a weekly basis: one location upstream of Ranger uranium mine and one location downstream. The total activity concentration of the alpha-emitting Ra-226 (dissolved and particulate radionuclides) was measured by high-resolution alpha spectrometry which achieves a detection limit down to $0.5 \mathrm{mBq} \cdot \mathrm{L}^{-1}$ following a procedure described in Sauerland et al. [8].

\section{RESULTS AND DISCUSSION}

\subsection{Human dose assessment: Current guidelines for radium 226 in Magela creek}

The limit of $10 \mathrm{mBq} \cdot \mathrm{L}^{-1}$ established for an increase above natural background in total Ra-226 concentration in surface waters downstream of the mine [4] is based on a dose constraint of $0.3 \mathrm{mSv}$ per year above natural background from the ingestion of Ra-226 in freshwater mussels (Velesunio angasi), a 10 year old child consuming $2 \mathrm{~kg}$ of mussels annually and a concentration factor of $19 \mathrm{~m}^{3} \cdot \mathrm{kg}^{-1}$ for Ra-226 from the water column [1]. It is applied to the arithmetic mean of the difference values between downstream and upstream sites for the wet season. This limit should not be exceeded due to mining activities.

Monitoring data for total Ra-226 activity concentrations over two wet seasons at the upstream and downstream locations, as well as their difference values, were normally distributed (Kolmogorov-Smirnov normality test). The boxplots of the three distributions (downstream, upstream and difference values), plotted with MINITAB 13.20 and shown in Figure 1a) and b), show outliers (represented by asterisks) for the upstream and difference value distributions.

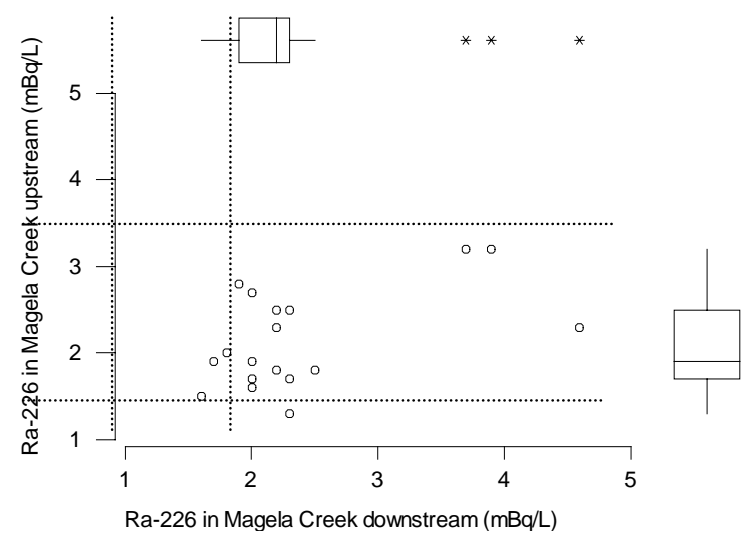

a)

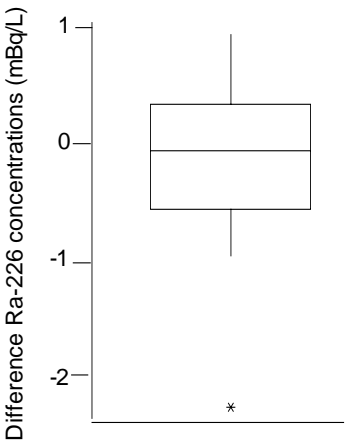

b)

Figure 1. a) Scatter plot of total Ra-226 activity concentrations at Magela Creek upstream and downstream (with boxplots in each direction in the margins of the $\mathrm{x}$ - and $\mathrm{y}$-axes) and b) boxplot of difference in total Ra-226 activity concentrations (downstream - upstream); asterisks represent outliers. 
Grubb's test, also termed the ESD method (extreme studentized deviate), was used to determine whether the most extreme values in the data are significant outliers. In all three distributions only the difference value of $-2.3 \mathrm{mBq} . \mathrm{L}^{-1}$ was identified as a significant outlier $(\mathrm{P}<0.05)$. This value was disregarded for the calculation of the wet season arithmetic mean difference.

The scatterplot in figure 1a) illustrates the greater range of the upstream data (with a standard error of 0.20 ) leaning towards higher Ra-226 activity concentrations compared to the downstream data (standard error of 0.13 ). This may be caused by the upstream and downstream data being not always hydrologically related. For example, for a particular storm event within the Magela Creek catchment, the resultant peak discharge occurs at the downstream site approximately $5 \mathrm{~h}$ after peak discharge occurs at the upstream site [9]. Because the time delay between the sampling at the upstream and at the downstream location is only a maximum of a few hours in most cases, and therefore less than the hydrological lagtime, difference values should not be calculated for individual samples. Instead, the downstream and the upstream distributions should be compared statistically - thereby avoiding outliers caused by the hydrological lagtime. For example, the means over the 2001-2002 and 2002-2003 wet seasons for both sites, $2.3 \mathrm{mBq} \cdot \mathrm{L}^{-1}$ at the upstream and $2.1 \mathrm{mBq} . \mathrm{L}^{-1}$ at the downstream site, are not significantly different ( 2 sample t-test, P-Value $=0.38, \mathrm{n}=19)$. However, in this instance, the difference between the means at both sites $\left(-0.2 \mathrm{mBq} \cdot \mathrm{L}^{-1}, \mathrm{n}=19\right)$ is close to the wet season arithmetic mean differences (-0.1 mBq. $\left.\mathrm{L}^{-1}\right)$ for both wet seasons 2001-2002 $(n=8)$ and 2002-2003 $(n=10)$.

A set of three trigger levels was defined for Ra-226 in Magela Creek for different time periods over which a radiological dose would be accumulated: a focus level was set at $10 \mathrm{mBq} \cdot \mathrm{L}^{-1}$ for the difference between upstream and downstream location for any measurement, an action level at a minimum of $10 \mathrm{mBq} . \mathrm{L}^{-1}$ difference over 90 consecutive days, and the above-mentioned limit level of $10 \mathrm{mBq} . \mathrm{L}^{-1}$ arithmetic mean of the difference values for the wet season [4]. Trigger values provide an early warning system for the management of the mine site for the purpose of protecting downstream ecosystems. However, Ra-226 data cannot be used for immediate operational purposes due to the time delays involved in analysis by alpha spectrometry. Instead, focus, action and limit levels are applied to suitable surrogate indicators of mine waste waters measured in the field ( $\mathrm{pH}$, electrical conductivity and turbidity) and for indicators measured by mass-spectrometric analysis (uranium and manganese).

In Figure 2, total Ra-226 activity concentrations are reported using a control chart approach with the current limit based on human radiological protection. None of the three trigger values were exceeded in the 2001-2002 and 2002-2003 wet seasons. With this approach, it is possible to retrospectively assess the difference in Ra-226 activity concentrations between upstream and downstream locations, (e.g.) after a wet season, to evaluate if a significant additional radiological dose was received by the critical group.

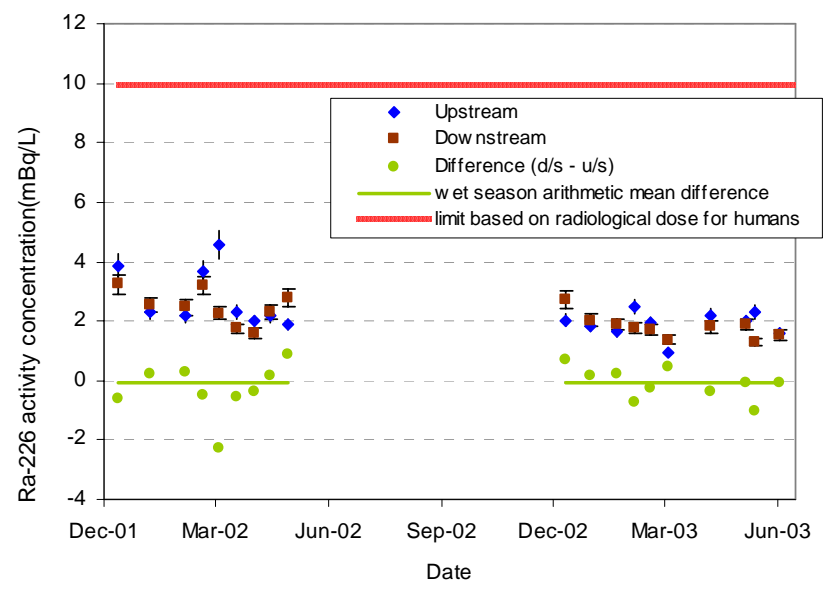

Figure 2. Total activity concentration of Ra-226 in Magela Creek (no water flow from June to December 2002). Errors represent one estimated standard deviation based on counting statistics. 


\subsection{Ecosystem health: Applying the revised Australian and New Zealand (ANZ) Water Quality Guidelines}

An important feature of the revised Australian and New Zealand Guidelines for Fresh and Marine Water Quality [6] is the risk-based approach taken for setting regional default guidelines, and the detailed assistance to tailor guidelines to local conditions rather than applying a fixed set of limit values. The ANZ water quality guidelines recommend three alternative procedures for establishing trigger values for chemical constituents (in decreasing order of preference):

1. Derive a site-specific limit based on the toxicity to local biota,

2. Derive site-specific trigger values based on distributional properties of a reference condition, and

3. Apply risk based regional and/or ecosystem-specific default guidelines dependant on the ecosystem condition. These may be toxicologically- or reference-condition-based.

Chemical toxicity of Ra is not considered to be an issue at the concentrations considered in this paper because Ra would need to be more toxic than uranium by a factor of about one million for chemical toxicity to be relevant. This is considered most unlikely. However, little is known about the radiotoxicity of Ra to animals. This issue is explored in more detail in the next section but here we consider the application of the second procedure listed above as a general approach to ecosystem protection. This procedure allows the derivation of site-specific triggers for Ra-226 for Magela Creek using the upstream data as the reference data set.

The reference dataset can be used to establish a range of distributional-threshold Ra-226 concentrations in Magela Creek. The focus, action and limit triggers (here taken as the $80^{\text {th }}, 95^{\text {th }}$ and $99^{\text {th }}$ percentiles of the reference data) for total Ra-226 activity concentrations in Magela Creek are $2.4 \mathrm{mBq} . \mathrm{L}^{-1}$, $3.9 \mathrm{mBq} . \mathrm{L}^{-1}$ and $4.4 \mathrm{mBq} \cdot \mathrm{L}^{-1}$ respectively. A median of the downstream monitoring data being higher than the $80^{\text {th }}$ percentile of the reference data, would be considered representative of a (statistically) significant increase. This approach allows for the assessment of trends in a highly variable system: peaks of Ra-226 concentrations are caused by the flushing of soils and finer sediments into Magela Creek (with high Ra-226 concentrations compared to those in the sandy creek bed [10]) during high rainfall events. Figure 3 illustrates the assessment of Ra-226 activity concentrations collected at the downstream site against these trigger levels.

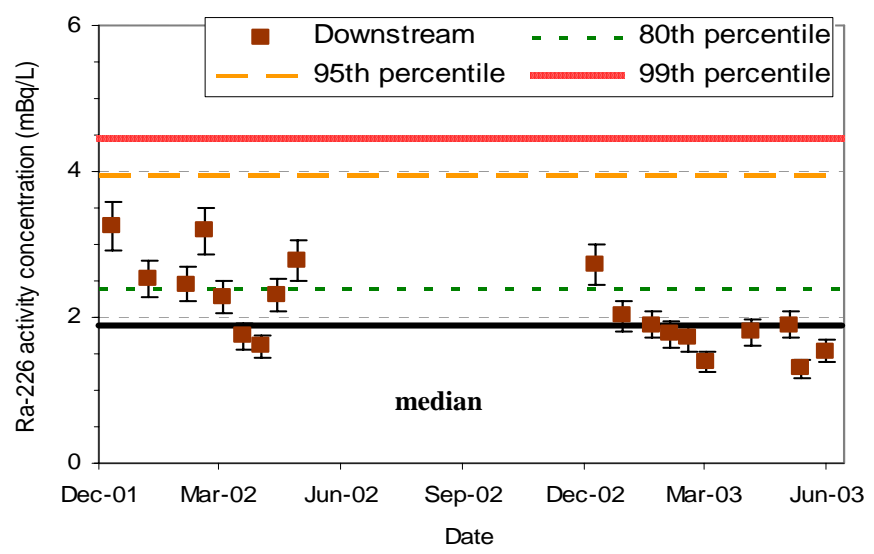

Figure 3. Total activity concentration of Ra-226 in Magela Creek downstream of the uranium mine assessed against a reference dataset (dashed lines represent percentiles of reference data).

Since the median of the data collected downstream of the uranium mine $\left(1.9 \mathrm{mBq} \cdot \mathrm{L}^{-1}\right)$ is below the $80^{\text {th }}$ percentile of the upstream data, it can be concluded that concentrations were maintained within natural variation. Consequently, there is no expectation of a significant additional dose to human or aquatic biota due to uranium mine operations. 


\subsection{Dose assessment of radium 226 for biota living in Magela Creek}

Johnston et al [11] calculated the weighted absorbed dose for nine species of biota resulting from a hypothetical release of four radionuclides (polonium, radium, thorium and uranium) into Magela Creek. They found that the freshwater mussel (Velesunio angasi) had absorbed doses at least one order of magnitude higher than any other studied organism and primarily (95\%) resulting from the alpha decay of bioaccumulated Ra-226.

We used a version of the spreadsheet program described by Copplestone et al [7] which has been modified [12] to include selected uranium series radionuclides. Deposition of natural radionuclides and trace metals in the sandy creek bed of Magela Creek is likely to be negligible [10]. Thus we have used total Ra-226 activity concentrations and a local concentration factor $\left(19 \mathrm{~m}^{3} . \mathrm{kg}^{-1}\right.$ from the water column [1]) assuming instantaneous uptake and excretion of Ra-226 to calculate the weighted absorbed dose for freshwater mussels. External dose rates were negligible compared to the internal dose rates and were not included in the estimations. Results are summarised in table 1.

Table 1. Estimated absorbed weighted internal doses to freshwater mussels (Velesunio angasi) at total Ra-226 activity concentrations in Magela Creek, corresponding to trigger values discussed in Sections 3.1 and 3.2 and to the highest concentration measured in any sample.

\begin{tabular}{|c|c|c|}
\hline $\begin{array}{l}\text { Comparison of doses to mussels residing } \\
\text { in waters at Ra-226 concentrations }\end{array}$ & $\begin{array}{c}\text { Activity concentration in } \\
\text { water }\left(\mathbf{m B q} \cdot \mathbf{L}^{-\mathbf{1}}\right)\end{array}$ & $\begin{array}{c}\text { Absorbed weighted } \\
\text { dose }\left(\boldsymbol{\mu} \mathbf{G y . h} \mathbf{h}^{-\mathbf{1}}\right)\end{array}$ \\
\hline Current limit based on human dose & 10.0 & 64 \\
\hline Triggers derived from reference data & 2.4 & 15 \\
\hline $80^{\text {th }}$ percentile (focus) & 3.9 & 25 \\
\hline $95^{\text {th }}$ percentile (action) & 4.4 & 28 \\
\hline $99^{\text {th }}$ percentile (limit) & 4.6 & 30 \\
\hline Maximum measured concentration & & 400 \\
\hline Dose rate 'limit' to freshwater biota [7] & & \\
\hline
\end{tabular}

For freshwater organisms, a dose rate of $400 \mu \mathrm{Gy} \cdot \mathrm{h}^{-1}$ is generally considered as being a dose rate below which significant effects are unlikely [7]. The weighted (internal) dose absorbed by freshwater mussels residing in Magela Creek at the highest measured Ra-226 concentration (4.6 mBq.L $\left.\mathrm{L}^{-1}\right)$ is estimated to be $30 \mu \mathrm{Gy} . \mathrm{h}^{-1}$. This dose is high, but occurs under natural conditions (see Section 3.2.). For Ra-226 activity concentrations below the current limit of $10 \mathrm{mBq} . \mathrm{L}^{-1}$, the estimated additional weighted absorbed dose due to mining would be below $64 \mu \mathrm{Gy} \cdot \mathrm{h}^{-1}$. Consequently, acute effects of Ra-226 on freshwater mussels, or any other aquatic organisms in Magela Creek, are unlikely when water quality complies with the current limit based on human dose assessment.

This outcome is in apparent disagreement to the findings of Johnston et al [11]. They found that the protection of aquatic animals rather than people would be the limiting factor when considering the effects of ionising radiation from a hypothetical waste water release into Magela Creek. The explanation lies in the extra conservatism that has been included in the derivation of the operational limit of $10 \mathrm{mBq} / \mathrm{L}$ for the concentration of Radium in creek waters. First, a dose constraint of $0.3 \mathrm{mSv}$ per annum was used instead of the public dose limit of $1 \mathrm{mSv}$ per annum used by Johnston et al. Second, since the operational concentration limit should apply at any time in a wet season, discharges throughout the entire wet season period have been assumed in estimating doses rather than the period of one month assumed by Johnston et al for a planned, significant discharge. Hence, the conclusion of Johnston et al remains valid for the specific comparison scenario considered by those authors. 


\section{CONCLUSION}

The three different approaches employed to apply guideline trigger values for total Ra-226 activity concentrations downstream of the Ranger uranium mine led to similar conclusions, based on the available data from the wet seasons 2001-2002 and 2002-2003. For each approach, the chosen indicators were below the respective limits and consistently indicated that a radiological impact on human and aquatic ecosystem health is unlikely. The limit calculated for human radiological protection may be considered as equivalent to a toxicologically derived limit, and its use in preference to a statistically derived (reference dataset) limit is consistent with the philosophy of the ANZ Water Quality Guidelines. The adopted limit of $10 \mathrm{mBq} \cdot \mathrm{L}^{-1}$ would preferentially be calculated as the difference of the wet season averages at the upstream and downstream sites. The comparison of statistics of the data collected downstream of the Ranger uranium mine with reference data can be used to retrospectively assess if Ra-226 activity concentrations have increased significantly above background due to mining activities and resulted in an additional dose for biota. For example, the comparison of a moving median of data collected at the downstream location with the $80^{\text {th }}$ percentile of the reference data would be appropriate to regularly assess trends in the radiological dose to the critical group.

\section{Acknowledgements}

The authors thank Peter Medley for radiochemical analysis and Energy Resources Australia for providing data for April, May and June 2003.

\section{References}

[1] Martin P., Hancock G.J., Johnston A. and Murray A.S., J. Env. Rad. 40 (1998) pp. 37-58.

[2] Johnston A., Murray A.S., Marten R., Martin P. \& Pettersson H. (1987). Bioaccumulation of radionuclides and stable metals in the freshwater mussel, Velesunio angasi. ARRRI Annual Research Summary 1986-87 pp. 69-74, Supervising Scientist for the Alligator Rivers Region, AGPS, Canberra.

[3] Jeffrey R.A., Verh. Int. Ver. Theor. Angew. Limnol. 22 (1985) pp. 2486 - 2942.

[4] Klessa D., Water Quality in Magela creek upstream and downstream of Ranger (Internal Report 380, Supervising Scientist, Darwin, 2001).

[5] ICRP, Age-dependant doses to members of the public from intake of radionuclides (Publication 72, International Commission on Radiological Protection, Pergamon Press, Oxford, 1996).

[6] ANZECC and ARMCANZ, Australian and New Zealand guidelines for fresh and marine water quality. (Australian and New Zealand Environment and Conservation Council \& Agriculture and Resource Management Council of Australia and New Zealand, Canberra, 2000); availabale on www.deh.gov.au/water/quality/nwqms/.

[7] Copplestone D., Bielby S., Jones S.R., Patton D., Daniel P. and Gize I., Impact assessment of ionising radiation on wildlife (R\&D Publication 128, Environment Agency, Bristol, 2001).

[8] Sauerland C., Iles M., Martin P. and Zapantis A., "Radium 226 in waters of the Magela creek catchment, Northern Australia”, 13th Conference of the Australian Institute of Nuclear Science and Engineering, Sydney, 26-28 November 2003, Eds. (Australian Institute of Nuclear Science and Engineering, Lucas Height, 2003) ISBN 0-9577217-9-X. pp. 86-88.

[9] Moliere D., personnel communication, Environmental Research Institute of the Supervising Scientist, 2004.

[10] Murray A.S., Johnston A., Martin P., Hancock G., Marten R. and Pfitzner J., J. of Hydrology 150 (1993) pp. 19-39.

[11] Johnston A., Humphrey C. and Martin P., "Protection of the environment from the effects of ionising radiation associated with uranium mining”, International Conference on the Protection of the Environment from the Effects of Ionizing Radiation, Stockholm, 6-10 October 2003, in press.

[12] Jones S., Copplestone D. and Zinger-Gize I., A method of impact assessment for ionising radiation on wildlife. In Protection of the Environment from Ionising Radiation, (IAEA Publication 17/P, IAEA, Vienna, 2003) pp. 248-256. 